\title{
Eight Personal Rules for Doing Science
}

Johan A.J. Metz (metz@rulsfb.leidenuniv.nl)

\section{Approved by}

Ulf Dieckmann

Program Leader, ADN

December 2005

Interim Reports on work of the International Institute for Applied Systems Analysis receive only limited review. Views or opinions expressed herein do not necessarily represent those of the Institute, its National Member Organizations, or other organizations supporting the work. 


\section{IIASA STUDIES IN ADAPTIVE DYNAMICS No. 104}

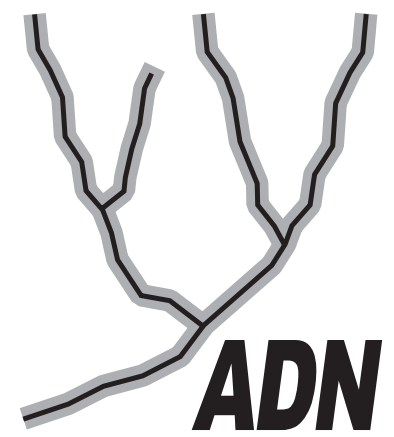

The Adaptive Dynamics Network at IIASA fosters the development of new mathematical and conceptual techniques for understanding the evolution of complex adaptive systems.

Focusing on these long-term implications of adaptive processes in systems of limited growth, the Adaptive Dynamics Network brings together scientists and institutions from around the world with IIASA acting as the central node.

Scientific progress within the network is collected in the IIASA Studies in Adaptive Dynamics series.

No. 1 Metz JAJ, Geritz SAH, Meszéna G, Jacobs FJA, van Heerwaarden JS: Adaptive Dynamics: A Geometrical Study of the Consequences of Nearly Faithful Reproduction. IIASA Working Paper WP-95-099 (1995). van Strien SJ, Verduyn Lunel SM (eds): Stochastic and Spatial Structures of Dynamical Systems, Proceedings of the Royal Dutch Academy of Science (KNAW Verhandelingen), North Holland, Amsterdam, pp. 183-231 (1996).

No. 2 Dieckmann U, Law R: The Dynamical Theory of Coevolution: A Derivation from Stochastic Ecological Processes. IIASA Working Paper WP-96-001 (1996). Journal of Mathematical Biology 34:579-612 (1996).

No. 3 Dieckmann U, Marrow P, Law R: Evolutionary Cycling of Predator-PreyInteractions: Population Dynamics and the Red Queen. IIASA Preprint (1995). Journal of Theoretical Biology 176:91-102 (1995).

No. 4 Marrow P, Dieckmann U, Law R: Evolutionary Dynamics of Predator-Prey Systems: An Ecological Perspective. IIASA Working Paper WP-96-002 (1996). Journal of Mathematical Biology 34:556-578 (1996).

No. 5 Law R, Marrow P, Dieckmann U: On Evolution under Asymmetric Competition. IIASA Working Paper WP-96-003 (1996). Evolutionary Ecology 11:485-501 (1997).

No. 6 Metz JAJ, Mylius SD, Diekmann O: When Does Evolution Optimize? On the Relation Between Types of Density Dependence and Evolutionarily Stable Life History Parameters. IIASA Working Paper WP-96-004 (1996).

No. 7 Ferrière R, Gatto M: Lyapunov Exponents and the Mathematics of Invasion in Oscillatory or Chaotic Populations. Theoretical Population Biology 48:126-171 (1995).

No. 8 Ferrière R, Fox GA: Chaos and Evolution. IIASA Preprint (1996). Trends in Ecology and Evolution 10:480485 (1995).

No. 9 Ferrière R, Michod RE: The Evolution of Cooperation in Spatially Heterogeneous Populations. IIASA Working Paper WP-96-029 (1996). The American Naturalist 147:692717 (1996).

No. 10 van Dooren TJM, Metz JAJ: Delayed Maturation in Temporally Structured Populations with Non-Equilibrium Dynamics. IIASA Working Paper WP-96-070 (1996). Journal of Evolutionary Biology 11:41-62 (1998).
No. 11 Geritz SAH, Metz JAJ, Kisdi É, Meszéna G: The Dynamics of Adaptation and Evolutionary Branching. IIASA Working Paper WP-96-077 (1996). Physical Review Letters 78:2024-2027 (1997).

No. 12 Geritz SAH, Kisdi É, Meszéna G, Metz JAJ: Evolutionary Singular Strategies and the Adaptive Growth and Branching of the Evolutionary Tree. IIASA Working Paper WP-96-114 (1996). Evolutionary Ecology 12:35-57 (1998).

No. 13 Heino M, Metz JAJ, Kaitala V: Evolution of Mixed Maturation Strategies in Semelparous Life-Histories: The Crucial Role of Dimensionality of Feedback Environment. IIASA Working Paper WP-96-126 (1996). Philosophical Transactions of the Royal Society of London Series B 352:1647-1655 (1997).

No. 14 Dieckmann U: Can Adaptive Dynamics Invade? IIASA Working Paper WP-96-152 (1996). Trends in Ecology and Evolution 12:128-131 (1997).

No. 15 Meszéna G, Czibula I, Geritz SAH: Adaptive Dynamics in a 2-Patch Environment: A Simple Model for Allopatric and Parapatric Speciation. IIASA Interim Report IR-97-001 (1997). Journal of Biological Systems 5:265-284 (1997).

No. 16 Heino M, Metz JAJ, Kaitala V: The Enigma of Frequency-Dependent Selection. IIASA Interim Report IR97-061 (1997). Trends in Ecology and Evolution 13:367-370 (1998).

No. 17 Heino M: Management of Evolving Fish Stocks. IIASA Interim Report IR-97-062 (1997). Canadian Journal of Fisheries and Aquatic Sciences 55:1971-1982 (1998).

No. 18 Heino M: Evolution of Mixed Reproductive Strategies in Simple Life-History Models. IIASA Interim Report IR-97063 (1997).

No. 19 Geritz SAH, van der Meijden E, Metz JAJ: Evolutionary Dynamics of Seed Size and Seedling Competitive Ability. IIASA Interim Report IR-97-071 (1997). Theoretical Population Biology 55:324-343 (1999).

No. 20 Galis F, Metz JAJ: Why Are There So Many Cichlid Species? On the Interplay of Speciation and Adaptive Radiation. IIASA Interim Report IR-97-072 (1997). Trends in Ecology and Evolution 13:1-2 (1998). 
No. 21 Boerlijst MC, Nowak MA, Sigmund K: Equal Pay for all Prisoners/ The Logic of Contrition. IIASA Interim Report IR-97-073 (1997). American Mathematical Society Monthly 104:303-307 (1997). Journal of Theoretical Biology 185:281-293 (1997).

No. 22 Law R, Dieckmann U: Symbiosis Without Mutualism and the Merger of Lineages in Evolution. IIASA Interim Report IR-97-074 (1997). Proceedings of the Royal Society of London Series B 265:1245-1253 (1998).

No. 23 Klinkhamer PGL, de Jong TJ, Metz JAJ: Sex and Size in Cosexual Plants. IIASA Interim Report IR-97-078 (1997). Trends in Ecology and Evolution 12:260-265 (1997).

No. 24 Fontana W, Schuster P: Shaping Space: The Possible and the Attainable in RNA Genotype-Phenotype Mapping. IIASA Interim Report IR-98-004 (1998). Journal of Theoretical Biology 194:491-515 (1998).

No. 25 Kisdi É, Geritz SAH: Adaptive Dynamics in Allele Space: Evolution of Genetic Polymorphism by Small Mutations in a Heterogeneous Environment. IIASA Interim Report IR-98-038 (1998). Evolution 53:993-1008 (1999).

No. 26 Fontana W, Schuster P: Continuity in Evolution: On the Nature of Transitions. IIASA Interim Report IR-98-039 (1998). Science 280:1451-1455 (1998).

No. 27 Nowak MA, Sigmund K: Evolution of Indirect Reciprocity by Image Scoring/ The Dynamics of Indirect Reciprocity. IIASA Interim Report IR-98-040 (1998). Nature 393:573-577 (1998). Journal of Theoretical Biology 194:561574 (1998).

No. 28 Kisdi É: Evolutionary Branching Under Asymmetric Competition. IIASA Interim Report IR-98-045 (1998). Journal of Theoretical Biology 197:149-162 (1999).

No. 29 Berger U: Best Response Adaptation for Role Games. IIASA Interim Report IR-98-086 (1998).

No. 30 van Dooren TJM: The Evolutionary Ecology of Dominance-Recessivity. IIASA Interim Report IR-98-096 (1998). Journal of Theoretical Biology 198:519-532 (1999).

No. 31 Dieckmann U, O'Hara B, Weisser W: The Evolutionary Ecology of Dispersal. IIASA Interim Report IR-98-108 (1998). Trends in Ecology and Evolution 14:88-90 (1999).

No. 32 Sigmund K: Complex Adaptive Systems and the Evolution of Reciprocation. IIASA Interim Report IR-98-100 (1998). Ecosystems 1:444-448 (1998).

No. 33 Posch M, Pichler A, Sigmund K: The Efficiency of Adapting Aspiration Levels. IIASA Interim Report IR-98103 (1998). Proceedings of the Royal Society London Series B 266:1427-1435 (1999).

No. 34 Mathias A, Kisdi É: Evolutionary Branching and Coexistence of Germination Strategies. IIASA Interim Report IR-99-014 (1999).

No. 35 Dieckmann U, Doebeli M: On the Origin of Species by Sympatric Speciation. IIASA Interim Report IR-99-013 (1999). Nature 400:354-357 (1999).

No. 36 Metz JAJ, Gyllenberg M: How Should We Define Fitness in Structured Metapopulation Models? Including an Application to the Calculation of Evolutionarily Stable Dispersal Strategies. IIASA Interim Report IR-99-019 (1999). Proceedings of the Royal Society of London Series B 268:499508 (2001)
No. 37 Gyllenberg M, Metz JAJ: On Fitness in Structured Metapopulations. IIASA Interim Report IR-99-037 (1999). Journal of Mathematical Biology 43:545-560 (2001).

No. 38 Meszéna G, Metz JAJ: Species Diversity and Population Regulation: The Importance of Environmental Feedback Dimensionality. IIASA Interim Report IR-99-045 (1999).

No. 39 Kisdi É, Geritz SAH: Evolutionary Branching and Sympatric Speciation in Diploid Populations. IIASA Interim Report IR-99-048 (1999).

No. 40 Ylikarjula J, Heino M, Dieckmann U: Ecology and Adaptation of Stunted Growth in Fish. IIASA Interim Report IR-99-050 (1999). Evolutionary Ecology 13:433-453 (1999).

No. 41 Nowak MA, Sigmund K: Games on Grids. IIASA Interim Report IR-99-038 (1999). Dieckmann U, Law R, Metz JAJ (eds): The Geometry of Ecological Interactions: Simplifying Spatial Complexity, Cambridge University Press, Cambridge, UK, pp. 135-150 (2000).

No. 42 Ferrière R, Michod RE: Wave Patterns in Spatial Games and the Evolution of Cooperation. IIASA Interim Report IR-99-041 (1999). Dieckmann U, Law R, Metz JAJ (eds): The Geometry of Ecological Interactions: Simplifying Spatial Complexity, Cambridge University Press, Cambridge, UK, pp. 318-332 (2000).

No. 43 Kisdi É, Jacobs FJA, Geritz SAH: Red Queen Evolution by Cycles of Evolutionary Branching and Extinction. IIASA Interim Report IR-00-030 (2000). Selection 2:161$176(2001)$.

No. 44 Meszéna G, Kisdi É, Dieckmann U, Geritz SAH, Metz JAJ: Evolutionary Optimisation Models and Matrix Games in the Unified Perspective of Adaptive Dynamics. IIASA Interim Report IR-00-039 (2000). Selection 2:193-210 (2001).

No. 45 Parvinen K, Dieckmann U, Gyllenberg M, Metz JAJ: Evolution of Dispersal in Metapopulations with Local Density Dependence and Demographic Stochasticity. IIASA Interim Report IR-00-035 (2000). Journal of Evolutionary Biology 16:143-153 (2003).

No. 46 Doebeli M, Dieckmann U: Evolutionary Branching and Sympatric Speciation Caused by Different Types of Ecological Interactions. IIASA Interim Report IR-00-040 (2000). The American Naturalist 156:S77-S101 (2000).

No. 47 Heino M, Hanski I: Evolution of Migration Rate in a Spatially Realistic Metapopulation Model. IIASA Interim Report IR-00-044 (2000). The American Naturalist 157:495$511(2001)$.

No. 48 Gyllenberg M, Parvinen K, Dieckmann U: Evolutionary Suicide and Evolution of Dispersal in Structured Metapopulations. IIASA Interim Report IR-00-056 (2000). Journal of Mathematical Biology 45:79-105 (2002).

No. 49 van Dooren TJM: The Evolutionary Dynamics of Direct Phenotypic Overdominance: Emergence Possible, Loss Probable. IIASA Interim Report IR-00-048 (2000). Evolution 54:1899-1914 (2000).

No. 50 Nowak MA, Page KM, Sigmund K: Fairness Versus Reason in the Ultimatum Game. IIASA Interim Report IR00-57 (2000). Science 289:1773-1775 (2000).

No. 51 de Feo O, Ferrière R: Bifurcation Analysis of Population Invasion: On-Off Intermittency and Basin Riddling. IIASA Interim Report IR-00-074 (2000). International Journal of Bifurcation and Chaos 10:443-452 (2000). 
No. 52 Heino M, Laaka-Lindberg S: Clonal Dynamics and Evolution of Dormancy in the Leafy Hepatic Lophozia Silvicola. IIASA Interim Report IR-01-018 (2001). Oikos 94:525-532 (2001).

No. 53 Sigmund K, Hauert C, Nowak MA: Reward and Punishment in Minigames. IIASA Interim Report IR-01-031 (2001). Proceedings of the National Academy of Sciences of the USA 98:10757-10762 (2001).

No. 54 Hauert C, De Monte S, Sigmund K, Hofbauer J: Oscillations in Optional Public Good Games. IIASA Interim Report IR-01-036 (2001).

No. 55 Ferrière R, Le Galliard J: Invasion Fitness and Adaptive Dynamics in Spatial Population Models. IIASA Interim Report IR-01-043 (2001). Clobert J, Dhondt A, Danchin E, Nichols J (eds): Dispersal, Oxford University Press, pp. 57-79 (2001).

No. 56 de Mazancourt C, Loreau M, Dieckmann U: Can the Evolution of Plant Defense Lead to Plant-Herbivore Mutualism. IIASA Interim Report IR-01-053 (2001). The American Naturalist 158:109-123 (2001).

No. 57 Claessen D, Dieckmann U: Ontogenetic Niche Shifts and Evolutionary Branching in Size-Structured Populations. IIASA Interim Report IR-01-056 (2001). Evolutionary Ecology Research 4:189-217 (2002).

No. 58 Brandt H: Correlation Analysis of Fitness Landscapes. IIASA Interim Report IR-01-058 (2001).

No. 59 Dieckmann U: Adaptive Dynamics of Pathogen-Host Interacations. IIASA Interim Report IR-02-007 (2002). Dieckmann U, Metz JAJ, Sabelis MW, Sigmund K (eds): Adaptive Dynamics of Infectious Diseases: In Pursuit of Virulence Management, Cambridge University Press, Cambridge, UK, pp. 39-59 (2002).

No. 60 Nowak MA, Sigmund K: Super- and Coinfection: The Two Extremes. IIASA Interim Report IR-02-008 (2002). Dieckmann U, Metz JAJ, Sabelis MW, Sigmund K (eds): Adaptive Dynamics of Infectious Diseases: In Pursuit of Virulence Management, Cambridge University Press, Cambridge, UK, pp. 124-137 (2002).

No. 61 Sabelis MW, Metz JAJ: Taking Stock: Relating Theory to Experiment. IIASA Interim Report IR-02-009 (2002). Dieckmann U, Metz JAJ, Sabelis MW, Sigmund K (eds): Adaptive Dynamics of Infectious Diseases: In Pursuit of Virulence Management, Cambridge University Press, Cambridge, UK, pp. 379-398 (2002).

No. 62 Cheptou P, Dieckmann U: The Evolution of SelfFertilization in Density-Regulated Populations . IIASA Interim Report IR-02-024 (2002). Proceedings of the Royal Society of London Series B 269:1177-1186(2002).

No. 63 Bürger R: Additive Genetic Variation Under Intraspecific Competition and Stabilizing Selection: A Two-Locus Study. IIASA Interim Report IR-02-013 (2002). Theoretical Population Biology 61:197-213 (2002).

No. 64 Hauert C, De Monte S, Hofbauer J, Sigmund K: Volunteering as Red Queen Mechanism for Co-operation in Public Goods Games. IIASA Interim Report IR-02-041 (2002). Science 296:1129-1132 (2002).

No. 65 Dercole F, Ferrière R, Rinaldi S: Ecological Bistability and Evolutionary Reversals under Asymmetrical Competition. IIASA Interim Report IR-02-053 (2002). Evolution 56:1081-1090 (2002).
No. 66 Dercole F, Rinaldi S: Evolution of Cannibalistic Traits: Scenarios Derived from Adaptive Dynamics. IIASA Interim Report IR-02-054 (2002). Theoretical Population Biology 62:365-374 (2002).

No. 67 Bürger R, Gimelfarb A: Fluctuating Environments and the Role of Mutation in Maintaining Quantitative Genetic Variation. IIASA Interim Report IR-02-058 (2002). Genetical Research 80:31-46 (2002).

No. 68 Bürger R: On a Genetic Model of Intraspecific Competition and Stabilizing Selection. IIASA Interim Report IR02-062 (2002). Amer. Natur. 160:661-682 (2002).

No. 69 Doebeli M, Dieckmann U: Speciation Along Environmental Gradients. IIASA Interim Report IR-02-079 (2002). Nature 421:259-264 (2003).

No. 70 Dercole F, Irisson J, Rinaldi S: Bifurcation Analysis of a Prey-Predator Coevolution Model. IIASA Interim Report IR-02-078 (2002). SIAM Journal on Applied Mathematics 63:1378-1391 (2003).

No. 71 Le Galliard J, Ferrière R, Dieckmann U: The Adaptive Dynamics of Altruism in Spatially Heterogeneous Populations. IIASA Interim Report IR-03-006 (2003). Evolution 57:1-17 (2003).

No. 72 Taborsky B, Dieckmann U, Heino M: Unexpected Discontinuities in Life-History Evolution under SizeDependent Mortality. IIASA Interim Report IR-03-004 (2003). Proceedings of the Royal Society of London Series B 270:713-721 (2003).

No. 73 Gardmark A, Dieckmann U, Lundberg P: LifeHistory Evolution in Harvested Populations: The Role of Natural Predation. IIASA Interim Report IR-03-008 (2003). Evolutionary Ecology Research 5:239-257 (2003).

No. 74 Mizera F, Meszéna G: Spatial Niche Packing, Character Displacement and Adaptive Speciation Along an Environmental Gradient. IIASA Interim Report IR-03-062 (2003). Evolutionary Ecology Research 5:363-382 (2003).

No. 75 Dercole F: Remarks on Branching-Extinction Evolutionary Cycles. IIASA Interim Report IR-03-077 (2003). Journal of Mathematical Biology 47:569-580 (2003).

No. 76 Hofbauer J, Sigmund K: Evolutionary Game Dynamics. IIASA Interim Report IR-03-078 (2003). Bulletin of the American Mathematical Society 40:479-519 (2003).

No. 77 Ernande B, Dieckmann U, Heino M: Adaptive Changes in Harvested Populations: Plasticity and Evolution of Age and Size at Maturation. IIASA Interim Report IR03-058 (2003). Proceedings of the Royal Society of London Series B-Biological Sciences 271:415-423 (2004).

No. 78 Hanski I, Heino M: Metapopulation-Level Adaptation of Insect Host Plant Preference and Extinction-Colonization Dynamics in Heterogeneous Landscapes. IIASA Interim Report IR-03-028 (2003). Theoretical Population Biology 63:309-338 (2003).

No. 79 van Doorn G, Dieckmann U, Weissing FJ: Sympatric Speciation by Sexual Selection: A Critical Re-Evaluation. IIASA Interim Report IR-04-003 (2004). American Naturalist 163:709-725 (2004).

No. 80 Egas M, Dieckmann U, Sabelis MW: Evolution Restricts the Coexistence of Specialists and Generalists - the Role of Trade-off Structure. IIASA Interim Report IR-04-004 (2004). American Naturalist 163:518-531 (2004). 
No. 81 Ernande B, Dieckmann U: The Evolution of Phenotypic Plasticity in Spatially Structured Environments: Implications of Intraspecific Competition, Plasticity Costs, and Environmental Characteristics. IIASA Interim Report IR-04-006 (2004). Journal of Evolutionary Biology 17:613-628 (2004).

No. 82 Cressman R, Hofbauer J: Measure Dynamics on a One-Dimensional Continuous Trait Space: Theoretical Foundations for Adaptive Dynamics. IIASA Interim Report IR04-016 (2004).

No. 83 Cressman R: Dynamic Stability of the Replicator Equation with Continuous Strategy Space. IIASA Interim Report IR-04-017 (2004).

No. 84 Ravigné V, Olivieri I, Dieckmann U: Implications of Habitat Choice for Protected Polymorphisms. IIASA Interim Report IR-04-005 (2004). Evolutionary Ecology Research 6:125-145 (2004).

No. 85 Nowak MA, Sigmund K: Evolutionary Dynamics of Biological Games. IIASA Interim Report IR-04-013 (2004). Science 303:793-799 (2004).

No. 86 Vukics A, Asbóth J, Meszéna G: Speciation in Multidimensional Evolutionary Space. IIASA Interim Report IR-04-028 (2004). Physical Review 68:041-903 (2003).

No. 87 de Mazancourt C, Dieckmann U: Trade-off Geometries and Frequency-dependent Selection. IIASA Interim Report IR-04-039 (2004). American Naturalist 164:765-778 (2004).

No. 88 Cadet CR, Metz JAJ, Klinkhamer PGL: Size and the Not-So-Single Sex: disentangling the effects of size on sex allocation. IIASA Interim Report IR-04-084 (2004). American Naturalist 164:779-792 (2004).

No. 89 Rueffler C, van Dooren TJM, Metz JAJ: Adaptive Walks on Changing Landscapes: Levins' Approach Extended. IIASA Interim Report IR-04-083 (2004). Theoretical Population Biology 65:165-178 (2004).

No. 90 de Mazancourt C, Loreau M, Dieckmann U: Understanding Mutualism When There is Adaptation to the Partner. IIASA Interim Report IR-05-016 (2005). Journal of Ecology 93:305-314 (2005).

No. 91 Dieckmann U, Doebeli M: Pluralism in Evolutionary Theory. IIASA Interim Report IR-05-017 (2005). Journal of Evolutionary Biology 18:1209-1213 (2005).

No. 92 Doebeli M, Dieckmann U, Metz JAJ, Tautz D: What We Have Also Learned. IIASA Interim Report IR-05-018 (2005). Evolution 59:691-695 (2005).
No. 93 Egas M, Sabelis MW, Dieckmann U: Evolution of Specialization and Ecological Character Displacement of Herbivores Along a Gradient of Plant Quality. IIASA Interim Report IR-05-019 (2005). Evolution 59:507-520 (2005).

No. 94 Le Galliard J, Ferrière R, Dieckmann U: Adaptive Evolution of Social Traits: Origin, Trajectories, and Correlations of Altruism and Mobility. IIASA Interim Report IR05-020 (2005). American Naturalist 165:206-224 (2005).

No. 95 Doebeli M, Dieckmann U: Adaptive Dynamics as a Mathematical Tool for Studying the Ecology of Speciation Processes. IIASA Interim Report IR-05-022 (2005). Journal of Evolutionary Biology 18:1194-1200 (2005).

No. 96 Brandt H, Sigmund K: The Logic of Reprobation: Assessment and Action Rules for Indirect Reciprocity. IIASA Interim Report IR-04-085 (2004). Journal of Theoretical Biology 231:475-486 (2004).

No. 97 Hauert C, Haiden N, Sigmund K: The Dynamics of Public Goods. IIASA Interim Report IR-04-086 (2004). Discrete and Continuous Dynamical Systems - Series B 4:575587 (2004).

No. 98 Meszéna G, Gyllenberg M, Jacobs FJA, Metz JAJ: Link Between Population Dynamics and Dynamics of Darwinian Evolution. IIASA Interim Report IR-05-026 (2005). Physical Review Letters 95:Article 078105 (2005).

No. 99 Meszéna G: Adaptive Dynamics: The Continuity Argument. IIASA Interim Report IR-05-032 (2005). Journal of Evolutionary Biology 18:1182-1185 (2005).

No. 100 Brännström NA, Dieckmann U: Evolutionary Dynamics of Altruism and Cheating Among Social Amoebas. IIASA Interim Report IR-05-039 (2005). Proceedings of the Royal Society London Series B 272:1609-1616 (2005).

No. 101 Meszéna G, Gyllenberg M, Pasztor L, Metz JAJ: Competitive Exclusion and Limiting Similarity: A Unified Theory. IIASA Interim Report IR-05-040 (2005).

No. 102 Szabo P, Meszéna G: Limiting Similarity Revisited. IIASA Interim Report IR-05-050 (2005).

No. 103 Krakauer DC, Sasaki A: The Greater than Two-Fold Cost of Integration for Retroviruses. IIASA Interim Report IR-05-069 (2005).

No. 104 Metz JAJ: Eight Personal Rules for Doing Science. IIASA Interim Report IR-05-069 (2005). Journal of Evolutionary Biology 18:1178-1181 (2005).

Issues of the IIASA Studies in Adaptive Dynamics series can be obtained at www.iiasa.ac.at/Research/ADN/Series.html or by writing to adn@iiasa.ac.at. 


\title{
Eight personal rules for doing science
}

\author{
J.A.J. Metz \\ Section Theoretical Biology, Institute of Biology, Leiden University, \\ P.O. Box 9516, NL-2300 RA Leiden, Netherlands \\ Adaptive Dynamics Network, Institute for Applied Systems Analysis, \\ A-2361 Laxenburg, Austria \\ email: metz@rulsfb.leidenuniv.nl
}

1. On structures and predictions: Adaptive dynamics (AD) is not a scientific theory, but a mathematical framework for dealing with eco-evolutionary problems, based on a varied set of simplifying assumptions as a means of approaching problems of otherwise greater complexity. As such it may be compared to e.g. the theory of stochastic processes, or of differential equations. AD can make predictions only in a similar way to these theories: it lays bare consistent patterns in mathematical structures, some of which hopefully connect to the real world. Predictions largely come from specific models. AD studies the tools for analysing such models. Like the theory of differential equations or bifurcation theory, a number of these tools already existed before the abstract theory took off. AD creates order on an abstract level, which in turn helps in constructing new tools. As far as the use of the newer tools is concerned, AD can be said to have contributed to predictions. Another class of predictions from AD arise from arguments on the frequency with which one may expect different situations to occur. A number of such predictions are present in my first paper on the subject (Metz et al., 1996). These are repeated, with one correction and with a few others added, in Box 4.8 in Geritz et al. (2004). Two more general predictions are discussed in Metz \& McCune (2004). These predictions mainly concern macro-evolutionary patterns, an area left singularly bare of predictions by the modern synthesis. It was precisely the longing for such predictions that started my personal search for the simplest possible dynamic extension of ESS theory, and thus got me hooked on AD.

2. On grouping people: There does not exist a well-defined AD community. There are presently at least three broad "schools": around Tom Vincent and Joel Brown, based on differential equations, control, and game theory; around Peter Abrams, based on Lande's equation and differential equation based community models; and the Europeans, focussing on limit arguments for individual-based ecological stochastic processes, and on abstract dynamical systems arguments. But even these slightly more homogeneous groups cannot be considered well-defined communities. I pride myself, being one of its godfathers, on the diversity within the European group. In my opinion science should be as anarchic as possible, lest social ties or propriety get in the way of the uninhibited search for truth. Moralising about group behaviour is improper and does not reflect the reality of the social situation.

Given my predilection for anarchy, below I only speak for myself, as others in the "community" should speak for topics that are closer to their heart than they are to mine.

3. On the reaches of biological theory: I entered evolutionary biology sideways at a rather late stage in my career. My two original backgrounds are old-fashioned naturalism and relatively abstract mathematics. For a proof that these scientific disciplines combine seamlessly see e.g. Diekmann et al. (2003), Gyllenberg et al. (2003), and Durinx \& Metz (2005).) My own contributions to AD directly reflect these backgrounds. I care for the biological detail seen in the field and despair about the amount to which this detail is assumed away in most of the theoretical biological 
literature. I sincerely feel that biological complexity may be abstracted away, in the sense that it is proven that it matters little once a certain level of abstraction is reached, but should never be assumed away, e.g. by assuming that all individuals are equivalent, dying and giving birth at random, as is done in most differential equation models. This does not mean that the latter models are worthless as they may be valuable representatives of an equivalence class of models all showing the same phenomenon. As such, these oversimplified models are good tools for discovering phenomena. But their eventual justification should come from their embedding in a larger class of models, some members of which connect more directly to the real biological world.

When during my first summer holidays after graduation I read Crow and Kimura's (1970) book on population genetics, I was at the same time carried away by its mathematical beauty and abhorred by the extent to which real biology, as I saw it from my tent, was missing. It is this feeling of imbalance that has guided my choices over the years, up to my present involvement with $\mathrm{AD}$. And, rather than trying to extend $\mathrm{AD}$ in the direction of population genetics, I prefer to work on its underpinning from the evodevo side (e.g. Galis et al., 2001, 2002; Galis \& Metz, 2001, 2003), as I believe that, as far as long term adaptive change is concerned, such an extension may well be more conducive to producing relevant predictions than me as a newcomer adding to the already awesomely large body of population genetical literature.

4. On simplifications: The simplifying assumptions of AD are presently largely made at the genetic end, just as population genetics tends to make its simplifications at the ecological end. These assumptions are extensively discussed in the two papers (Dieckmann \& Law, 1996; Metz et al., 1996) that laid out the "European research program". One assumption is clonal reproduction. This assumption was made in order to concentrate on and treat in some generality the ecological side of evolutionary change, a side that I still feel to be underrepresented not so much in the specific as in the general theoretical evolutionary literature. The idea was that first identifying the evolutionarily relevant common properties of large classes of ecological processes would provide a good basis for slowly reintroducing more genetical detail. A purely ecological assumption made initially was the uniqueness of ecological attractors. Clearly, both assumptions, clonal reproduction and uniqueness of ecological attractors, can be considerably relaxed. However, it is easier to do so from an established reference platform. Presently, I and many other Europeans are working hard at determining the extent to which such a relaxation of assumptions can be effected (e.g. Geritz et al., 2002; Jacobs \& Metz, 2003; Geritz, 2004; Metz, 2006). The second set of "assumptions" referred to specifically in $\mathrm{W} \& \mathrm{G}$ are actually not assumptions as such but limit arguments. The difference is small, but relevant in the present context. An assumption delimits a class of models. A limit argument constructs a particular class of models from a larger or different class as a means of obtaining insight into this larger class. Judging the performance of limit models is done in two steps, with step 1 discussing the region of parameter space where the approximation does a good job, and step 2 discussing where in parameter space one expects particular real systems to be located. The two main limits used in AD are based on mutation limitation and phenotypic smallness of mutational steps. Interestingly, by embedding the AD models in a still larger class, step 2 for these limits also can be brought partially within the theoretical as opposed to the empirical realm. The picture emerging from constructional morphology and evo-devo is one of very high dimensional trait spaces and very ridgy fitness landscapes. Due to the high dimension of the trait space, the top of the ridges may be higher dimensional, although relatively low dimensional compared to the offridge directions. The slopes at the top of the ridges are the domain of ecology and thus of $\mathrm{AD}$, while their overall location is largely ecology independent. The combination of this picture with an argument in the spirit of Fisher's argument on curvature effects in high dimensional spaces (Fisher, 1930; revived and extended by Sean Rice, 1990), 
suggests that the parameter regions where the limit procedures favoured by AD work well, should contain their fair share of real cases, as by far the most mutations, and in particular those with large effect, end up in the fitness abyss.

5. On earth friendlyness: I believe that scientific writing should be as compact as possible, within the constraints that adherence to mathematical truth and precision takes precedence. The goal is producing results and not cutting down trees. I am proud that there is little overlap between the content of my diverse publications. After I have written something, I prefer not to repeat it, but to rely on citations. This may be one reason why $\mathrm{W} \& \mathrm{G}$ believe that assumptions are left implicit; in the suites of papers of which I am co-author these assumptions are discussed carefully on the first occasion and after that are repeated only as compactly as possible. In a similar vein, I see citing primarily as a means for shortening papers; in particular, citing should not lead to extensions of the text just in order to connect it with remoter material. Here my background in mathematics shines through. What matters is that a paper contains a well-crafted consistent argument, relatively complete within its confines. Elucidating historical connections is best left to historians, who in general will do a better, or at least less biased, job.

6. On citing: Here are two concrete examples. (i) W\&G feel that the AD crowd should cite what they consider precursors of AD's "gradient dynamics". Wright's gradient dynamics (Wright, 1935) is defined on a space of gene frequencies as opposed to phenotypes. Russ Lande's gradient dynamics (Lande, 1976) deals with biologically similar problems but rests on a mathematically different foundation, as it considers a different limiting regime. If the connection is in the concept of gradient dynamics only, then priority goes to the physical and mathematical literature. However, the "gradient dynamics" of AD is not a gradient dynamics at all, as the gradient is taken with respect to one of the variables in a function of two variables, while the dynamics takes place in the other of the two variables. So citing the older literature without further explanation is mathematically improper. When an explanation does not contribute to the intrinsic clarity of the arguments of a paper, then this explanation does not belong there, valuable though it would be were it published in a historical or review paper.

(ii) I learned the use of Pairwise Invasibility Plots from van Tienderen \& de Jong (1986), but they are present already in Matsuda (1985). Matsuda's PIPs I missed, for which I already apologised to him in person. (I confess to preferring to roam novel territory in the few weeks that I have per year for research, instead of combing the older literature for potential predecessors, especially since in this literature the topics that have my main interest usually appear as side issues only.) Freddy Bugge Christiansen's and Volker Loeschcke's (1980) PIP I also initially was unaware of, but I was informed by Freddy. However, they present their PIP primarily as a parameter plot in a short-term evolutionary context, without overtly connecting it to the adaptive random walk. For me PIPs and the adaptive walk come as a package deal; my citing does not refer to the plot but to its use.

I admire the work of Ronald Fisher, J.B.S. Haldane, Sewall Wright, Ilan Eshel, Russ Lande, Peter Taylor, and Freddy Bugge Christiansen, to name but a few of the great population geneticists. They did and do a marvellous job, and I very much enjoyed my efforts, to name one example, to make my way through Freddy's 1999 book. However, admiration is not a proper basis for writing scientific prose.

7. On ecological generality and mathematical elegance: The trick that AD uses to reach ecological generality starts with the introduction of the environment $E$ as an intervening variable (actually, this "variable" should be interpreted as a probability measure on time functions). This concept of environment is much more general than just a weighted average of population densities. Due to this trick invasion fitness can always be defined, 
also for stably fluctuating physiologically and spatially structured polymorphic resident populations, by substituting for $E$ the ecological attractor for the resident types. The cost paid is that fitnesses are not defined for the overlapping transient polymorphisms that without mutation limitation occur during evolutionary transients, for these do not support well-defined stationary environments. (Under the very restrictive simplifying assumption of viability selection and non-overlapping generations it is also possible to talk about fitnesses during population genetical transients, but these are instantaneous as opposed to overall fitnesses, and certainly not invasion fitnesses.) The invasion fitness function $s$ follows by eliminating the intervening variable $E$. (AD workers most often use the symbol $s$ for continuous time invasion fitness, for its allusion to a selection coefficient, while discrete time fitness is denoted as $w$; so $s=\ln (w)$. Below I will adhere to this tradition.) Somewhat surprisingly this very general framework leads to a few very strong results due to the necessary presence of ecological consistency conditions like $s(x ; x)=0[\Leftrightarrow w(x ; x)=1], s\left(x_{1} ; x_{1}, x_{2}\right)=s\left(x_{2} ; x_{1}, x_{2}\right)=0, s\left(y ; x_{1}, x_{2}\right)=s\left(y ; x_{2}, x_{1}\right)$, and in an evolutionarily singular point $s\left(y ; x^{*}, x^{*}\right)=s\left(y ; x^{*}\right)$. I appreciate W\&G's start from the familiar world of population genetics textbooks. However, in so doing they play down utterly the beauty and ecological generality that comes from using no more than the simplest, undisputed ecological laws. They even go so far as to write about the fitness difference $w(y ; x)-w(x ; x)$, instead of $w(y ; x)-1$, or, better still, the sign-equivalent $s(y ; x)$, ignoring that from the outset not only the concepts but also the notation of European $\mathrm{AD}$ were crafted to achieve the maximal economy of arguments and formulas. (My preference for any particular notational system is necessarily context dependent. On other occasions the classical population genetical notation does a better job. However, one should never spurn the advantages a particular system may have for the job at hand.)

8. On terminological precision: One of my goals in life is to make biology as exact a science as possible, on a par with physics and chemistry. I am (despite my great admiration for John Maynard Smith) still fighting a losing battle against the misnomer evolutionarily stable strategy. I was just lucky that the term Evolutionarily Singular Strategy, which was chosen for purely mathematical reasons, actually may serve as a minor weapon in this war. Although too much purism is objectionable, I should point out that evolutionarily singular points are not equilibrium points as is suggested by $\mathrm{W} \& \mathrm{G}$. A point in case is a branching point. If the adaptive walk starts exactly in a branching point it will not stay there. The definition of an equilibrium point is: once there, and no extraneous noise, then stay there. W\&G revert to apparent purism when it comes to the term branching point. Let me defend myself by pointing out that branching points are those points where ecologically branching can occur, which is not to say that it will occur. Whether it indeed occurs depends on non-ecological factors like the genetic architecture. I have no watertight rules for naming concepts. One thing is clear though, when parsing names one has to account for the context (in the case at hand the focus on ecology). Otherwise, one may e.g. naively conclude that a random variable is normally distributed since it represents a measurement on a normal phenomenon.

Lest this comment ends on too negative a note, let me finish by saying that I am thankful to Sergey Gavrilets and David Waxman for the effort they took to read through and summarise the AD literature from their perspective. As we all unfortunately know too well, building bridges is not the easiest of jobs. And I for one am most thankful that they tried their hands on a job which I, focused as I am on arguments instead of people, never would have dared to tackle.

Acknowledgement: The writing of this Comment was supported in part by The Academy of Finland. 


\section{References}

Christiansen, F. B. 1999. Population Genetics of Multiple Loci. Wiley, Chichester.

Christiansen, F. B. \& Loeschcke, V. 1980. Evolution and intraspecific exploitative competition: I. One-locus theory for small additive gene effects. Theor. Pop. Biol. 18: 297-313.

Crow, J. F. \& Kimura, M. 1970. An Introduction to Population Genetics Theory. Harper and Row, New York.

Dieckmann, U. \& Law, R. 1996. The dynamical theory of coevolution: A derivation from stochastic ecological processes. J. Math. Biol. 34: 579-612.

Diekmann, O., Gyllenberg, M. \& Metz, J.A.J. 2003. Steady state analysis of structured population models. Theor. Pop. Biol. 63:309-338.

Durinx, M. \& Metz, J.A.J. 2005. Multi-type branching processes and adaptive dynamics of structured populations. Section 7.8 in P. Haccou, P. Jagers \& V. Vatutin: Branching Processes in Biology: Variation, Growth and Extinction. Cambridge University Press.

Fisher, R. A. 1930. The Genetical Theory of Natural Selection. Oxford University Press.

Galis, F. \& Metz, J.A.J. 2001. Testing the vulnerability of the phylotypic stage: on modularity and evolutionary conservation. J. Exp. Zool. (Mol. Dev. Evol.) 291: 195-204.

Galis, F. \& Metz, J.A.J. 2003. Anti-cancer selection as a source of developmental and evolutionary constraints. Bioessays 25: 1035-1039.

Galis, F., van Alphen, J.J.M. \& Metz, J.A.J. 2001. Why do we have five fingers? The evolutionary constraint on digit numbers. TREE 16: 637-646.

Galis, F., van Dooren, T. \& Metz, J.A.J. 2002. Conservation of the segmented germband stage: modularity and robustness or pleiotropy and stabilizing selection? TIG 18: 504-509.

Geritz, S.A.H. 2004. Resident-invader dynamics and the coexistence of similar strategies. $J$. Math. Biol.

Geritz S.A.H., Gyllenberg M., Jacobs F.J.A. \& Parvinen, K. 2002. Invasion dynamics and attractor inheritance J. Math. Biol. 44: 548-560.

Geritz, S.A.H., Kisdi, É., Meszéna G. \&Metz J.A.J. 2004. Adaptive dynamics of speciation: ecological underpinnings. p. 54-75 in U. Dieckmann, J.A.J. Metz, M. Doebeli \& D. Tautz (eds.) Adaptive Speciation. Cambridge University Press.

Gyllenberg, M., Jacobs, F.J.A. \& Metz, J.A.J. 2003. On the concept of attractor in communitydynamical processes II: The case of structured populations. J. Math. Biol. 47: 235-248.

Jacobs, F.J.A. \& Metz, J.A.J. 2003. On the concept of attractor in community-dynamical processes I: The case of unstructured populations. J. Math. Biol. 47: 222-234

Lande R. 1976. Natural selection and random genetic drift in phenotypic evolution. Evolution 30: $314-334$

Matsuda, H., 1985. Evolutionarily stable strategies for predator switching. J. Theor. Biol. 115: 351-366.

Metz, J.A.J. 2006. Invasion fitness, canonical equations, and global invasibility criteria for Mendelian populations. In U. Dieckmann \& J.A.J. Metz (eds.) Elements of Adaptive Dynamics. Cambridge University Press.

Metz, J.A.J., Geritz, S.A.H., Meszéna, G., Jacobs, F.J.A. \& van Heerwaarden, J.S. 1996. Adaptive dynamics, a geometrical study of the consequences of nearly faithful reproduction. p. 183-231 in S.J. van Strien \& S.M. Verduyn Lunel (eds.) Stochastic and Spatial Structures of Dynamical Systems. North-Holland, Amsterdam.

Metz, J.A.J. \& McCune A.R. 2004. Box 18.2: Predictions from the changing geometry of fitness landscapes. p. 372-373 in A.R. McCune: Diversity and speciation of semionotid fishes in mesozoic rift lakes. p. 362-379 in U. Dieckmann, J.A.J. Metz, M. Doebeli \& D. Tautz (eds.) Adaptive Speciation. Cambridge University Press.

Rice, S. H. 1990. A geometric model for the evolution of development. J. Theor. Biol. 143: 319342.

van Tienderen, P.H. \& de Jong, G. 1986. Sex-ratio under the haystack model - polymorphism may occur. J. Theor. Biol. 122: 69-81. 